\title{
Validation of Spectrophotometric Hemoglobin Measurement with a Pulse Co-Oximeter in Cases of Massive Hemorrhage
}

\author{
Takako Kato, Yusuke Kasuya, Makoto Ozaki \\ Department of Anesthesiology, Tokyo Women's Medical University, Tokyo, Japan \\ Email: umetomomo928@gmail.com
}

How to cite this paper: Kato, T., Kasuya, Y. and Ozaki, M. (2017) Validation of Spectrophotometric Hemoglobin Measurement with a Pulse Co-Oximeter in Cases of Massive Hemorrhage. Open Journal of Anesthesiology, 7, 194-201.

https://doi.org/10.4236/ojanes.2017.77021

Received: June 22, 2017

Accepted: July 24, 2017

Published: July 27, 2017

Copyright $\odot 2017$ by authors and Scientific Research Publishing Inc. This work is licensed under the Creative Commons Attribution International License (CC BY 4.0).

http://creativecommons.org/licenses/by/4.0/

\begin{abstract}
Purpose: The accuracy of spectrophotometric hemoglobin ( $\mathrm{SpHb}$ ) measurement with a pulse co-oximeter was analyzed in cases of intraoperative massive hemorrhage and compared with $\mathrm{Hb}$ levels determined through blood gas analysis (LabHb) as a reference. We aimed to determine the extent to which in vivo adjustment (ADJ) for results of initial blood gas analysis would improve the accuracy of $\mathrm{SpHb}$ measurement. Methods: Data on LabHb and SpHb levels were collected from cases with hemorrhage of $1000 \mathrm{~g}$ or more. Correlations and Bland-Altman analyses were used to determine the associations between data before and after ADJ. Results: ADJ slightly improved the correlation coefficient (Pearson $\mathrm{r}$ ) between $\mathrm{SpHb}$ and LabHb levels from 0.65 to 0.72 . In Bland-Altman analysis, ADJ reduced the bias from $1.76 \pm 1.47 \mathrm{~g} / \mathrm{dL}$ to 0.64 $\pm 1.43 \mathrm{~g} / \mathrm{dL}$, while the $95 \%$ limits of agreement of -1.12 to $4.64 \mathrm{~g} / \mathrm{dL}$ (range: $5.77 \mathrm{~g} / \mathrm{dL}$ ) without ADJ improved to -2.16 to $3.44 \mathrm{~g} / \mathrm{dL}$ (range: $5.59 \mathrm{~g} / \mathrm{dL}$ ) with $\mathrm{ADJ}$. In four-quadrant analysis, other than samples in the exclusion zone, the total number analyzed was 326 , and the concordance rate was $82 \%$. Conclusion: Although the accuracy of $\mathrm{SpHb}$ measurement improves on ADJ, $\mathrm{SpHb}$ measurement cannot substitute for LabHb levels, and it is necessary to determine $\mathrm{Hb}$ levels with blood gas analysis in the laboratory. It remains unclear which measurement is superior for determining when to initiate blood transfusion to achieve better outcomes. To comply with conventional methods, LabHb measurements may be necessary.
\end{abstract}

\section{Keywords}

Pulse Co-Oximeter, Spectrophotometric Hemoglobin, Noninvasive and Continuous Hemoglobin, Perfusion Index 


\section{Introduction}

Massive intraoperative hemorrhage is frequently encountered during anesthetic management. Prompt and accurate measurement of hemoglobin ( $\mathrm{Hb}$ ) levels is important for rapid, appropriate treatment with fluid and blood transfusions in the event of massive hemorrhage. The standard method used for rapid measurement of $\mathrm{Hb}$ levels employs a laboratory blood gas analyzer. The recent development of a pulse co-oximeter (Radical-7; Masimo Corp., Irvine, CA, USA) for percutaneous monitoring has enabled spectrophotometric $\mathrm{Hb}(\mathrm{SpHb})$ measurement. To improve the precision of SpHb levels, in vivo adjustment (ADJ) is considered important [1]. In this study, we analyzed improvements in the precision of $\mathrm{SpHb}$ measurement in patients with massive intraoperative hemorrhage following preoperative $\mathrm{ADJ}$, and compared $\mathrm{SpHb}$ measurements with $\mathrm{Hb}$ levels determined with blood gas analysis $(\mathrm{LabHb})$ used as a reference.

\section{Methods}

\subsection{Subjects}

This retrospective observational study was conducted with approval from the ethics committee of Tokyo Women's Medical University (Approval No. 3522, August 4, 2015). This study included adult patients who underwent surgery under general anesthesia at the university between January 1 and November 30, 2014 and whose volume of intraoperative hemorrhage was $1000 \mathrm{~g}$ or more. A study flow chart is shown in Figure 1.

\subsection{Data Collection and Analyses}

A Radical-7, version 7.8 (sensor used: Rainbow R1 25-L, version Rev. K) pulse co-oximeter with an adhesive spectrophotometric sensor was placed on the tip of the index or middle finger to measure $\mathrm{SpHb}$ shortly after arrival in the operating room. Following induction of general anesthesia, an arterial catheter was placed in the radial artery on the same side as the $\mathrm{SpHb}$ sensor to monitor arterial

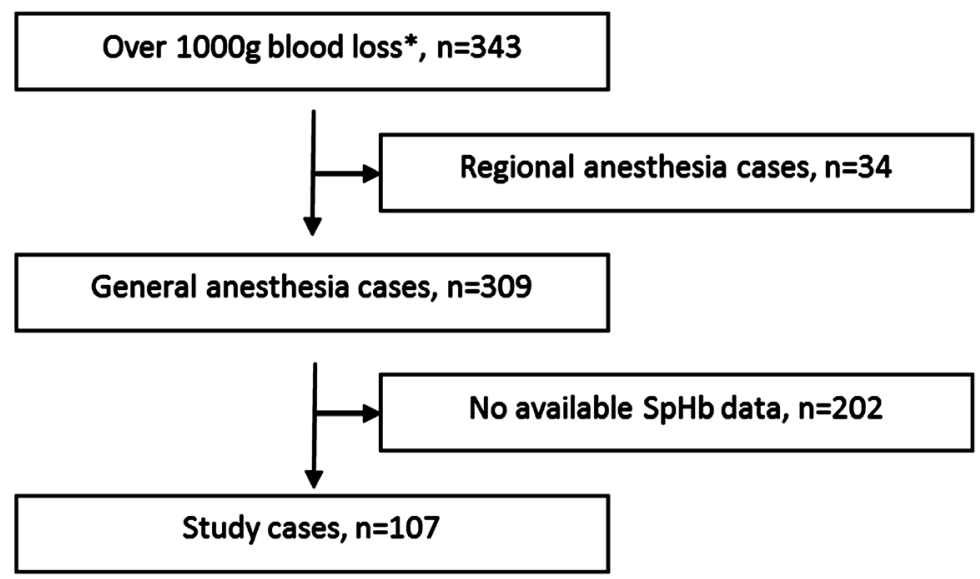

Figure 1. A study flow chart. There were 343 cases with hemorrhage more than $1000 \mathrm{~g}$ between January 1 and November 30, 2014. 
blood pressure and to sample blood gas. Blood samples were drawn from the arterial catheter and analyzed with the automatic gas analyzer (Critical Care Express; Nova Biomedical Corp., Waltham, MA USA) Initial LabHb measurement was performed at the start of the operation. In this retrospective study, anesthesia method, infusion and transfusion were not managed following a specific protocol. Anesthesiologists allowed to provide their own management plan respectively.

Data on $\mathrm{Hb}$ levels measured with blood gas analysis ( $\mathrm{LabHb}$ ), and $\mathrm{SpHb}$ levels measured with the CO-oximeter, were retrospectively collected from the anesthesia information management system. LabHb and $\mathrm{SpHb}$ levels at each time point of blood gas analysis were evaluated using correlation analysis, BlandAltman analysis, and four-quadrant analysis. GraphPad Prism 6 (La Jolla, CA USA) was used for statistical analyses. In Bland-Altman analysis, the difference and mean of $\mathrm{SpHb}$ and $\mathrm{LabHb}$ were plotted, and bias and 95\% limits of agreement were calculated.

The difference between the initial values for $\mathrm{SpHb}$ and $\mathrm{LabHb}$ was used for in-vivo adjustment. An adjusted $\mathrm{SpHb}(\mathrm{ADJHb})$ was calculated using the following formula;

$$
\mathrm{ADJHb}=\mathrm{SpHb}-\left(1^{\mathrm{st}} \mathrm{SpHb}-1^{\mathrm{st}} \mathrm{LabHb}\right)
$$

The values of $\mathrm{ADJHb}$ and $\mathrm{LabHb}$ were compared, and the same analyses using the above-described methods were also then performed. In addition, a BlandAltman subanalysis under conditions of maintained peripheral circulation was also performed, with data obtained only when the perfusion index (PI), an indicator of peripheral circulation, was 2.0 or greater.

In four-quadrant analysis, the amount of change in consecutive $\mathrm{SpHb}$ measurements over time $(\triangle \mathrm{SpHb})$ was plotted on a vertical axis, and the amount of change in consecutive LabHb measurements over time $(\Delta \mathrm{LabHb})$ was plotted on a horizontal axis. The degree of concordance between temporal changes in these measurements was then assessed. The exclusion zone was defined as $\Delta \mathrm{SpHb}$ or $\Delta \mathrm{LabHb}$ less than $0.3 \mathrm{~g} / \mathrm{dL}$, because these values indicated minute changes and seemed to be overestimated. The concordance rate was determined as the ratio of data plotted in the first and third quadrants to all plotted data, other than those in the exclusion zone.

\section{Results}

Blood gas analysis was performed using a total of 457 samples obtained from 107 patients. The patient demographics and procedures are shown in Table 1: gender, 53 men and 54 women; age, $59 \pm 17$ years; weight, $60 \pm 15 \mathrm{~kg}$; and height, 160 $\pm 9 \mathrm{~cm}$. The median and interquartile range of hemorrhage was 1600 (1215-2406) $\mathrm{g}$, and the mean volume of erythrocyte transfusion was $1028 \pm 920 \mathrm{~g}$.

ADJ slightly improved the correlation coefficient (Pearson $r$ ) between $\mathrm{SpHb}$ and LabHb levels from 0.65 to 0.72 (Figure 2(a) and Figure 2(b)). In the Bland-Altman analysis, the bias was $1.76 \pm 1.47 \mathrm{~g} / \mathrm{dL}$ without ADJ (Figure 3(a)) 
Table 1. The patient demographics and procedures.

\begin{tabular}{cc}
\hline Demographics & $\mathrm{N}=107$ \\
\hline Sex (Male/Female) & $53 / 54$ \\
Age (years) & $59 \pm 17$ \\
Weight (kg) & $60 \pm 15$ \\
Height (cm) & $160 \pm 9$ \\
Blood loss (g) & $1600(1215-2406)$ \\
Erythrocyte transfusion (g) & $1028 \pm 920$ \\
Surgery type cases (\%) & \\
Orthopedic & $44(41.1)$ \\
Obstetric and gynecological & $24(22.4)$ \\
Urological & $23(21.5)$ \\
Thoracotomy & $5(4.7)$ \\
Upper abdominal & $5(4.7)$ \\
Lower abdominal & $4(3.7)$ \\
Cardiac & $2(1.9)$
\end{tabular}

Demographics are presented as mean $\pm \mathrm{SD}$ and type of procedures are presented as numbers with percentage.

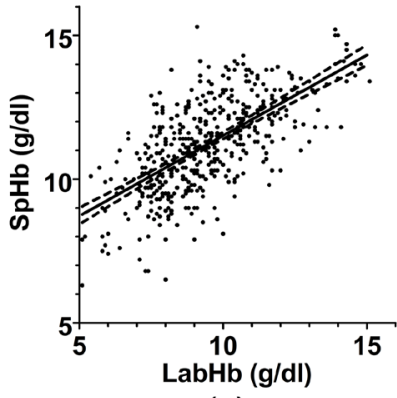

(a)

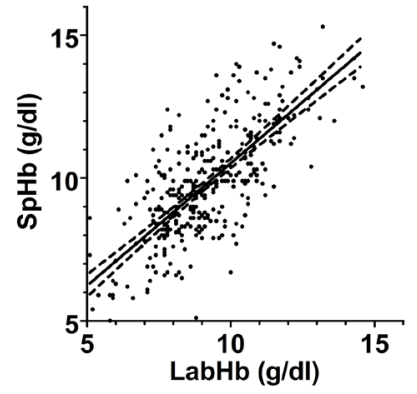

(b)

Figure 2. (a) Correlation analysis of $\mathrm{SpHb}$ and $\mathrm{LabHb}$ without in vivo adjustment; Total paired data $=457$, Pearson $r=0.65, p<0.01$; Slope: $0.56 \pm 0.03$, Y-intercept: $5.91 \pm 0.29$; (b) Correlation analysis of $\mathrm{SpHb}$ and $\mathrm{LabHb}$ with in vivo adjustment; Total paired data $=$ 351, Pearson $\mathrm{r}=0.72, \mathrm{p}<0.01$; Slope: $0.86 \pm 0.04$, Y-intercept: $1.94 \pm 0.41$.

and $0.64 \pm 1.43 \mathrm{~g} / \mathrm{dL}$ with ADJ (Figure $3(\mathrm{~b})$ ). The $95 \%$ limits of agreement were -1.12 to $4.64 \mathrm{~g} / \mathrm{dL}$ (range: $5.77 \mathrm{~g} / \mathrm{dL}$; Figure 3(a)) without ADJ and -2.16 to 3.44 g/dL (range: 5.59 g/dL; Figure 3(b)) with ADJ. Furthermore, under the condition of $\mathrm{PI} \geq 2.0$, the $95 \%$ limits of agreement were -0.68 to $4.54 \mathrm{~g}$ (range: 5.23 g/dL; Figure 3(c)) without ADJ and -1.60 to $3.43 \mathrm{~g} / \mathrm{dL}$ (range: $5.03 \mathrm{~g} / \mathrm{dL}$; Figure 3(d)) with ADJ, respectively.

In four-quadrant analysis (Figure 4), the total number of samples was 350, the exclusion zone was $10 \%(\Delta \mathrm{Hb}< \pm 0.3 \mathrm{~g} / \mathrm{dL})$, the total number of excluded samples was 24 , the total number of analyzed samples was 326 , and the concordance rate was $82 \%$. 


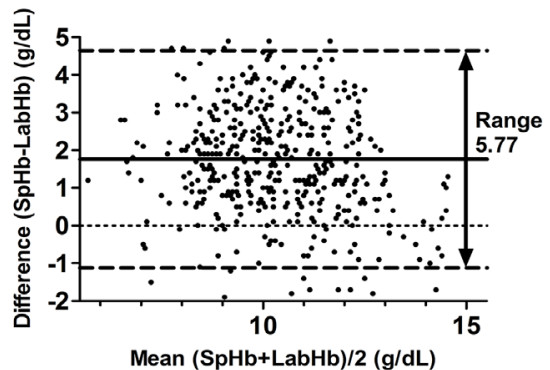

(a)

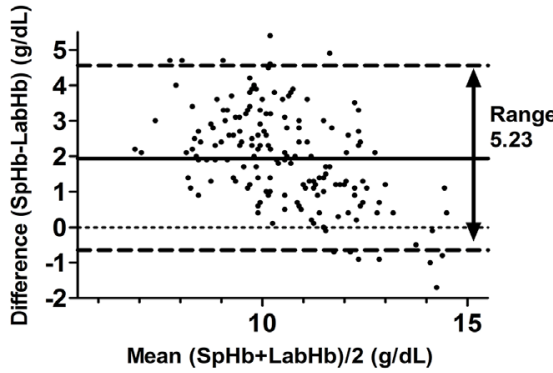

(c)

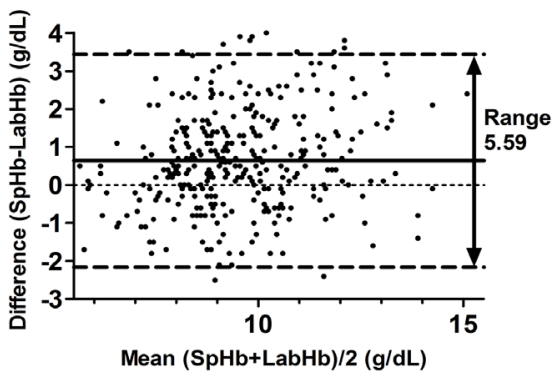

(b)

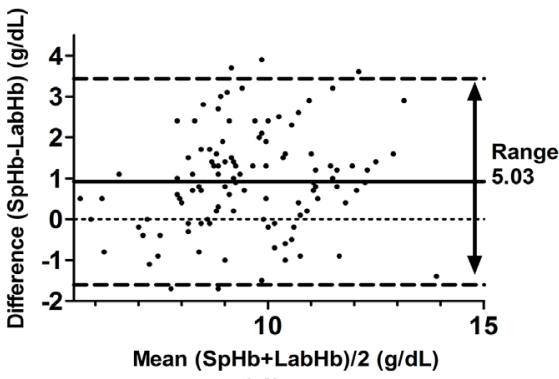

(d)

Figure 3. Bland-Altman plots. SpHb: Spectrophotometric hemoglobin levels measured with pulse co-oximeter (Radical-7; Masimo Corp., Irvine, CA, USA); LabHb: Hemoglobin levels measured with an automatic blood gas analyzer; Vertical axis: Differences between $\mathrm{SpHb}$ and LabHb; Horizontal axis: Mean of the SpHb and LabHb; Bland-Altman plots with bias (solid line) and 95\% limits of agreement (dashed line). (a) 457 data pairs without in vivo adjustment. Bias \pm 1SD: $1.76 \pm 1.47 \mathrm{~g} / \mathrm{dL}, 95 \%$ Limits of agreement: $5.77 \mathrm{~g} / \mathrm{dL}$ $(-1.12$ - $4.64 \mathrm{~g} / \mathrm{dL})$; (b) 351 data pairs with in vivo adjustment. Bias $\pm 1 \mathrm{SD}: 0.64 \pm 1.43$ g/dL, $95 \%$ Limits of agreement: $5.59 \mathrm{~g} / \mathrm{dL}(-2.16-3.44 \mathrm{~g} / \mathrm{dL})$; (c) 172 data pairs associated with a perfusion index $(\mathrm{PI}) \geq 2.0 \%$ without in vivo adjustment. Bias $\pm 1 \mathrm{SD}: 1.93 \pm 1.33$ g/dL, 95\% Limits of agreement: $5.23 \mathrm{~g} / \mathrm{dL}(-0.68-4.54 \mathrm{~g} / \mathrm{dL})$; (d) 117 data pairs associated with a perfusion index $(\mathrm{PI}) \geq 2.0 \%$ with in vivo adjustment. Bias \pm 1 SD: $0.92 \pm 1.28$ $\mathrm{g} / \mathrm{dL}, 95 \%$ Limits of agreement: $5.03 \mathrm{~g} / \mathrm{dL}(-1.6-3.43 \mathrm{~g} / \mathrm{dL})$.

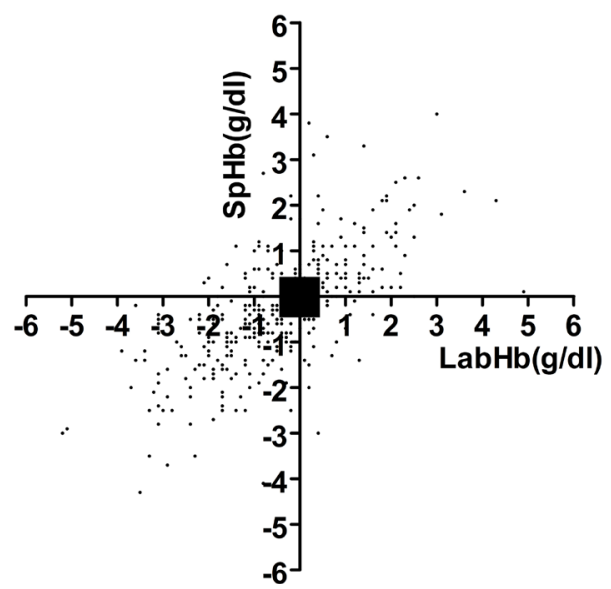

Figure 4. Four quadrant plots of $\mathrm{SpHb}$ and LabHb. $\Delta \mathrm{SpHb}$ : The amount of change in consecutive spectrophotometric hemoglobin measurements over time; $\Delta \mathrm{LabHb}$ : the amount of change in consecutive hemoglobin levels measured with an automatic blood gas analyzer over time; Of 350 total data points, 24 were excluded from analysis based on a $10 \%$ exclusion zone (delta $\Delta \mathrm{Hb}<0.3 \mathrm{~g} / \mathrm{dL}$ ). In the analysis, concordance (ratio in first and third quadrant) was $82 \%$. 


\section{Discussion}

In general, $\mathrm{SpHb}$ levels without $\mathrm{ADJ}$ tended to be higher than LabHb levels, and a comparison of both measurements obtained at the time point of initial blood gas analysis showed the following association: mean $\mathrm{SpHb}=\mathrm{LabHb}+1.36 \mathrm{~g} / \mathrm{dL}$ (maximum, $+4.9 \mathrm{~g} / \mathrm{dL}$; minimum, $-2.3 \mathrm{~g} / \mathrm{dL}$ ). Thus, when an initial $\mathrm{SpHb}$ level does not undergo $\mathrm{ADJ}$, making a decision on intraoperative administration of blood transfusion according to subsequent $\mathrm{SpHb}$ levels alone may delay treatment for critical massive hemorrhage, and could be associated with additional risk. In massive hemorrhage cases, the blood gas $\mathrm{Hb}$ value is the most important index for transfusion decision-making, and $15 \%-20 \%$ bias would be a clinically acceptable maximum range.

Moreover, without ADJ, the difference between SpHb and LabHb measurements increased as the mean $\mathrm{Hb}$ level decreased. A slight, right-hand-downward pattern was observed for the distribution (Figure 3(a) and Figure 3(c)). However, ADJ corrected the biased distribution (Figure 3(b) and Figure 3(d)), reduced the bias to approximately one-third, and limited the range of the $95 \%$ limits of agreement; therefore, it is necessary to match SpHb levels to LabHb levels at the time point of initial blood gas analysis.

Several reports have shown that the accuracy of SpHb levels is high in patients with good peripheral circulation, i.e., patients with a high PI ( $\geq 4.0)$ [2], and those with relatively small fluctuations in hemodynamics due to minor hemorrhage or other conditions [1] [3] [4] [5]. However, SpHb levels are considered to be less precise in patients requiring frequent $\mathrm{Hb}$ measurement, such as those with postoperative hemorrhage after cardiac surgery [6] or peripheral hypoperfusion [2]. In this study, we performed additional analyses under the condition of PI levels $\geq 2.0$, based on some reports [6] [7]. However, several other studies have reported analyses performed under conditions of PI levels $\geq 1.4$ [1] [2] [8]. Although some of these latter reports have shown improved accuracy [8], this improvement does not appear to be substantial [2]. Because our study only included patients with massive hemorrhage of $1000 \mathrm{~g}$ or more, with peripheral circulatory states that presumably fluctuated more than normal, we used a moderate PI level of $\geq 2.0$ as a cutoff point. For SpHb levels with or without ADJ in patients with PI levels of $\geq 2.0$, the correlation coefficients increased, the precision (i.e., one standard deviation) was improved, and the ranges of the $95 \%$ limits of agreement were reduced. This suggested that $\mathrm{SpHb}$ levels measured with a pulse co-oximeter were relatively reliable in cases with favorable peripheral circulation at the fingertip.

When hemodynamics greatly fluctuate because of massive hemorrhage and other conditions, the peripheral circulatory state becomes unstable; therefore, it is important to determine $\mathrm{Hb}$ levels with blood gas analysis in a conventional manner. Instead of relying on adjusted SpHb levels as absolute values, it may be important to use these as clinical indicators for determining whether to give blood or fluid transfusions while monitoring changes in the intraoperative course, 
PI, and Pleth Variability Index.

The four-quadrant analysis concordance rate was $82 \%$, which was not sufficiently high, even in comparison with rates described in other reports [9] [10].

As blood gas $\mathrm{Hb}$ levels were measured from the radial artery and $\mathrm{SpHb}$ was measured at the fingertip, these were derived from different samples. Although there are no reports of underlying systematic differences between peripheral arterial and central compartment $\mathrm{Hb}$, massive hemorrhage might affect the peripheral circulation, and could create central and peripheral deviation. Therefore, temporal change in $\mathrm{SpHb}$ was not an adequately accurate indicator for estimation of $\mathrm{Hb}$ level in the event of massive hemorrhage. Because of retrospective study, the limitation of this study was that the timing of the arterial blood sampling has not been preoperatively determined and the threshold $\mathrm{Hb}$ level for transfusion was not standardized. This study did not assess the $\mathrm{Hb}$ level change to evaluate the effectiveness of transfusion. Through continuous measurement, $\mathrm{SpHb}$ has a potential advantage in cases of sudden massive bleeding, when it is difficult to measure true bleeding volume (e.g., caesarean delivery blood combined with amniotic fluid, transurethral resectionwith perfusate); thus, $\mathrm{SpHb}$ might provide the anesthesiologist with information on changes in $\mathrm{Hb}$ levels earlier than blood gas sampling, and can enable an earlier response to bleeding.

\section{Conclusion}

Although $\mathrm{ADJ}$ reduces discordance between $\mathrm{SpHb}$ and $\mathrm{LabHb}$, conventional LabHb measurement with blood gas analysis is essential for important clinical decisionmaking in case of massive hemorrhage.

\section{References}

[1] Miyashita, R., Hirata, N., Sugino, S., Mimura, M. and Yamakage, M. (2014) Improved Non-Invasive Total Haemoglobin Measurements after In-Vivo Adjustment. Anaesthesia, 69, 752-756. https://doi.org/10.1111/anae.12681

[2] Miller, R.D., Ward, T.A., Shiboski, S.C. and Cohen, N.H. (2011) A Comparison of Three Methods of Hemoglobin Monitoring in Patients Undergoing Spine Surgery. Anesthesia \& Analgesia, 112, 858-863. https://doi.org/10.1213/ANE.0b013e31820eecd1

[3] Macknet, M.R., Allard, M., Applegate 2nd, R.L. and Rook, J. (2010) The Accuracy of Noninvasive and Continuous Total Hemoglobin Measurement by Pulse CO-Oximetry in Human Subjects Undergoing Hemodilution. Anesthesia \& Analgesia, 111, 1424-1426. https://doi.org/10.1213/ANE.0b013e3181fc74b9

[4] Berkow, L., Rotolo, S. and Mirski, E. (2011) Continuous Noninvasive Hemoglobin Monitoring During Complex Spine Surgery. Anesthesia \& Analgesia, 113, 1396 1402. https://doi.org/10.1213/ANE.0b013e318230b425

[5] Frasca, D., Dahyot-Fizelier, C., Catherine, K., Levrat, Q., Debaene, B. and Mimoz, O. (2011) Accuracy of a Continuous Noninvasive Hemoglobin Monitor in Intensive Care Unit Patients. Critical Care Medicine, 39, 2277-2282. https://doi.org/10.1097/CCM.0b013e3182227e2d

[6] Nguyen, B.V., Vincent, J.L., Nowak, E., Coat, M., Paleiron, N., Gouny, P., Ould- 
Ahmed, M., Guillouet, M., Arvieux, C.C. and Gueret, G. (2011) The Accuracy of Noninvasive Hemoglobin Measurement by Multiwavelength Pulse Oximetry after Cardiac Surgery. Anesthesia \& Analgesia, 113, 1052-1057.

https://doi.org/10.1213/ANE.0b013e31822c9679

[7] Miller, R.D., Ward, T.A., McCulloch, C.E. and Cohen, N.H. (2012) Does a Digital Regional Nerve Block Improve the Accuracy of Noninvasive Hemoglobin Monitoring? Journal of Anesthesia, 26, 845-850. https://doi.org/10.1007/s00540-012-1452-0

[8] Isosu, T., Obara, S., Hosono, A., Ohashi, S., Nakano, Y., Imaizumi, T., Mogami, M. and Murakawa, M. (2013) Validation of Continuous and Noninvasive Hemoglobin Monitoring by Pulse CO-Oximetry in Japanese Surgical Patients. Journal of Clinical Monitoring and Computing, 27, 55-60. https://doi.org/10.1007/s10877-012-9397-2

[9] Colquhoun, D.A., Forkin, K.T., Durieux, M.E. and Thiele, R.H. (2012) Ability of the Masimo Pulse CO-Oximeter to Detect Changes in Hemoglobin. Journal of Clinical Monitoring and Computing, 26, 69-73. https://doi.org/10.1007/s10877-012-9335-3

[10] Marques, N.R., Kramer, G.C., Voigt, R.B., Salter, M.G. and Kinsky, M.P. (2015) Trending, Accuracy, and Precision of Noninvasive Hemoglobin Monitoring during Human Hemorrhage and Fixed Crystalloid Bolus. Shock, 44, 45-49.

https://doi.org/10.1097/SHK.0000000000000310

\section{Scientific Research Publishing}

Submit or recommend next manuscript to SCIRP and we will provide best service for you:

Accepting pre-submission inquiries through Email, Facebook, LinkedIn, Twitter, etc. A wide selection of journals (inclusive of 9 subjects, more than 200 journals)

Providing 24-hour high-quality service

User-friendly online submission system

Fair and swift peer-review system

Efficient typesetting and proofreading procedure

Display of the result of downloads and visits, as well as the number of cited articles

Maximum dissemination of your research work

Submit your manuscript at: http://papersubmission.scirp.org/

Or contact ojanes@scirp.org 